\title{
DIATHERMY HAEMORRHOIDECTOMY; UNDER LOCAL ANAESTHESIA
}

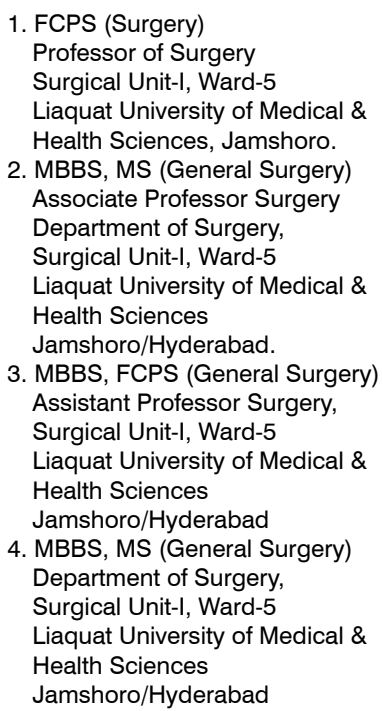

3. MBBS, FCPS (General Surgery) Assistant Professor Surgery,

Surgical Unit-I, Ward-5

Liaquat University of Medical \& Health Sciences Jamshoro/Hyderabad

4. MBBS, MS (General Surgery)

Department of Surgery,

Surgical Unit-I, Ward-5

Liaquat University of Medical \&

Health Sciences

Jamshoro/Hyderabad

\section{Correspondence Address:}

Dr. Abdul Razaque Shaikh

Flat no 208

Tayab Complex Sadder Cantt.

Hyderabad

Article received on:

14/01/2016

Accepted for publication:

21/06/2016

Received after proof reading:

08/08/2016

\section{INTRODUCTION}

Hemorrhoids is health problem since prehistoric time. ${ }^{1}$ Hemorrhoids develop from naturally occurring anal cushions within the lower rectum. Commonly there are three of these cushions and classically described as occupying the 3,7 and 11 O'clock position with the subject in the lithotomy position. ${ }^{2}$ Haemorrhoids is a common problem confronted by every practicing surgeon. National data is not available however the magnitude of problem is tremendous as evident by greater than $4 \%$ prevalence in United states. ${ }^{3}$

The common symptoms of Haemorrhoidal disease include bleeding, irritation, fullness, prolapse, difficult hygiene and seepage. ${ }^{4}$ These symptoms usually, but not always, depend upon

\begin{abstract}
Prof. A. Razaque Shaikh1, Dr. Abdul Ghafoor Dalwani ${ }^{2}$, Dr. Champa Sushel ${ }^{3}$, Dr. Ahmed Halepoto
STRACT... Objectives: Hemorrhoids is a common ano-rectal disorder, and heamorridectomy a circumscribed area of body by localized effect on peripheral nerve endings. The aim of this study is determine long term and short term outcome of diathermy haemorrhoidectomy under local anesthesia, in term of early recovery, hospital stay, postoperative pain, bleeding

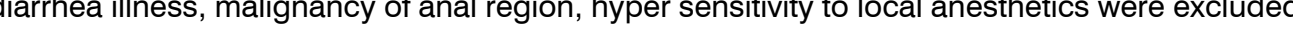
patients of haemorrhoidectomy were included. The mean operative time was 15.04 minutes (n $=50) .9(18.0 \%, n=50)$ patients had the complaint of pain, $15(30.0 \%, n=50)$ patients had ching around anus. Postoperatively $9(18.0 \%, n=50)$ patients got pain relief within one week, post operative bleeding was observed within the one week. Two patients $(4.0 \%, n=50)$ had

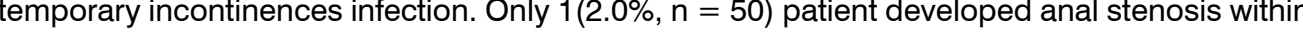
the long term period of one month to 1 year. Conclusion: Diathermy hemorrhoidectomy under
\end{abstract} Key words: Haemorrhiodectomy, local anaesthesia, diathermy 10.17957/TPMJ/16.3249

the grade of hemorrhoid(s). The Surgical excision of haemorrhoids has been present for centuries but the most popular technique for almost a century is the Milligon-Morgon, described in 1937. ${ }^{5}$ These classical technique uses scissors to excise the haemorrhoid leaving a mucosal bridge between each wound to prevent anal stenosis, the wounds are left open to heal by secondary intention. Haemostasis is then secured by use of diathermy. haemorrhoid is dealt with in the same manner; however, well-established skin bridges between each V-shaped segment of excised skin must remain. At the end of the operation, an anal speculum is inserted to be absolutely certain that there is complete haemostasis.

In1957 Ferguson ${ }^{6}$ described "closed technique' 
where mucosal edges sutured with aim to improve postoperative pain and accelerate wound healing. Various technical modifications have so far been practiced to decrease postoperative pain and shorten recovery period; that include, lateral internal sphincterecotomy, diathermy haemorrhoidectomy and use of anal sphincter relaxants like glycerol trinitrate (GTN) ointment or postoperative use of metronidazole. Although this technology had defenders, none has resulted in decreased postoperative pain enough to gain universal acceptance. ${ }^{7}$

It is hoped that a small number of patients that can lead surgeon, local anesthesia to patients who hemorrhoidectomy offer, as this promotes the presentation of hospital. ${ }^{8}$ It is well accepted that the constipation with consequent straining predisposes to hemorrhoids, however it has been shown that diarrhea may also be a risk factor. ${ }^{9}$ One of the important causes of Hemorrhoids has been attributed to the wrong posturing as the use of sitting toilets. ${ }^{10}$ Obesity, pregnancy, insufficient liquids intake and vitamin $\mathrm{E}$ deficiency also plays a part. The haemorrhoidectomy can be performed under different anesthetic alternatives including general anesthesia, spinal anesthesia, laryngeal mask anesthesia (LMA), intravenous general anesthesia (intravenous sedation) combined with local anesthesia, or perianal anesthetics infiltration. ${ }^{11}$ Few accessible conservative nonsurgical treatment. Surgical treatment options for choice when conservative treatment has failed or disease. ${ }^{12}$ Haemorrhoidectomy under local anesthesia reduced postoperative pain, analgesic requirements, and postoperative complications, and can be performed as daycase procedure. Diathermy haemorrhoidectomy reduced operating time and was equally effective than conventional haemorrhoidectomy in longterm symptom control. ${ }^{13}$

So most patients with advanced degree hemorrhoids or after exhausting their resources into the hands of quacks or present to be reluctant to adequate consultation for the initial stages of their illness, because search of cultural self. ${ }^{14}$ The most common issues connected surgical hemorrhoidectomy, are postoperative pain, bleeding and strictures. Numerous studies on (hemorrhoidectomy open and closed) in Pakistan and abroad, the advantage over the other, very little to choose between them. ${ }^{15,16}$

\section{MATERIAL AND METHODS}

This Cross sectional descriptive case series study was conducted 50 patients of haemorrhoidectomy between 24-02-2014 to 2402-2015 at the Department of General Surgery, Liaquat University of Medical and Health Sciences Jamshoro/ Hyderabad. All patients of III and IV degree haemorrhoid, which are fit for surgery were included whereas those patients who had previous anal surgery, co-existing disease i.e. Crohn's disease, chronic diarrhea illness, malignancy of anal region, hyper sensitivity to local analgesics were excluded from the study. A detailed relevant clinical history was taken and physical examination was done along the standard lines including general, systemic and local examination.

\section{Preoperative preparation}

Preanaesthetic evaluation was done and a soap water enema was given in the night before and on the morning of the surgery. Patients were kept nil orally from the previous night. Antibiotics were given on the day of surgery, before the procedure. Patients were explained about the effects and complications of the procedure.

\section{RESULTS}

Total 50 patients of hemorrhoids were included based on inclusion criteria. The mean age + SD (range) was $45.2+13.2$ (18 to 70 years). Most of the patients $19(38.0 \%, n=50)$ were observed in the age group 31 to 40 years, $14(28.0 \%, n=$ 50) patients were seen between 20 to 30 years of age while $11(22.0 \%, n=50)$ patients were in the age group of 41 to 50 years and $6(12.0 \%, n$ $=50$ ) patients were found in the age $>50$ years (Table-l). The mean operative time was 15.04 minutes ( $\mathrm{n}=50), 26(52.0 \%, \mathrm{n}=50$ ) patients had the duration of hospital stay up to 2 days, $22(44.0 \%, n=50)$ cases had the duration between 2 to 4 days while only $2(4.0 \%, n=50)$ patients had the duration $>4$ days. Out of 50 patients, 33(66.0\%) were males and $17(34.0 \%)$ 
were females. In this study, $9(18.0 \%, \mathrm{n}=50)$ patients had the complaint of pain, $15(30.0 \%, \mathrm{n}=$ $50)$ patients had itching around anus, $10(20.0 \%$, $\mathrm{n}=50$ ) developed diarrhea.

\begin{tabular}{|l|c|c|}
\hline \multicolumn{1}{|c|}{ Variable } & No. Patients & Percentage \\
\hline Gender & & \\
\hline Male & 33 & $66 \%$ \\
\hline Female & 17 & $34 \%$ \\
\hline Age & & \\
\hline $20-30$ years & 14 & $28 \%$ \\
\hline $31-40$ years & 19 & $38 \%$ \\
\hline $41-50$ years & 11 & $22 \%$ \\
\hline > 50 years & 6 & $12 \%$ \\
\hline Intensity of pain (n = 50) & \\
\hline Mild & 6 & $12 \%$ \\
\hline Moderate & 0 & 0 \\
\hline Severe & 0 & 0 \\
\hline Hospital stay & & \\
\hline up to 2 days & 26 & $52 \%$ \\
\hline 2 to 4 days & 22 & $44 \%$ \\
\hline$>4$ days & 02 & \\
\hline & & \\
\hline
\end{tabular}

Symptoms duration was between 5 months to 5 years. The mean duration of first symptom was 1.81 years. Out of 50 patients, $6(12.0 \%)$ patients had mild intensity of pain with gripping in nature. According to aggravating factors, $30(60.0 \%$, n $=50)$ patients complained for hard stool, while $5(10.0 \%, n=50)$ patients had complained long sitting. Relieving factors were observed in all the patients. $35(70.0 \%, n=50)$ patients were relieved by passage of soft stool while $15(30.0 \%, n=50)$ patients got relief by using laxatives.

Postoperatively $9(18.0 \%, n=50)$ patients got pain relief within one week, no post operative bleeding was observed within the one week. Two patients $(4.0 \%, n=50)$ had temporary incontinences infection. Only $1(2.0 \%, n=50)$ patient developed anal stenosis within the long term period of one month to 1 year (Table-II).

\begin{tabular}{|l|c|c|}
\hline \multicolumn{1}{|c|}{ Variable } & No. Patients & Percentage \\
\hline Short term (up to 1 week) & \multicolumn{2}{|c|}{} \\
\hline Pain & 9 & $18 \%$ \\
\hline Bleeding & 0 & $0 \%$ \\
\hline Temporary incontinence & 2 & $4 \%$ \\
\hline Long term (one month to 1 year) & \\
\hline Permanent incontinence & 0 & $0 \%$ \\
\hline Reoccurrence & 0 & $0 \%$ \\
\hline Anal stenosis & 1 & $2 \%$ \\
\hline \multicolumn{2}{|c|}{ Table-Il. Follow-up visits of the patients $(\mathrm{n}=\mathbf{5 0})$} \\
\hline
\end{tabular}

\section{DISCUSSION}

Local anesthesia (LA) to an operation of hemorrhoids with the aim of controlling pain which usually complicate the procedure ${ }^{17}$. Operation is done under LA there are other priorities. These benefits include early mobilization following discharge from the hospital, a reduction in the overall cost of the process and puts the doctor patient communication during the process. ${ }^{18}$ All these benefits are seen more appropriate in the areas where are the majority of our patients at the center belong to low socio-economic status and where a lot of misconceptions about the causes of hemorrhoids often. Seen number of patients in our center are afraid postoperative problems and hence, most decline surgery even when indicated.

Another recent study has shown that pain can be achieved and the use of local anesthesia to process if the patient medically fit and mentally prepared. ${ }^{19,20}$ In this study, mean age was 45.2 years and majority of the patients $19(38.0 \%, n=$ $50)$ were between the age group 31 to 40 years. Alatise Ol et al. ${ }^{17}$ also reported the mean age 44.73 years and he also observed that majority of patients were between the age group 31 to 40 years in his study which correlates well to this study. Another local study of Afridi $\mathrm{N}$ et al. ${ }^{21}$ conducted in Peshawar who showed the mean age 48.7 years which is also comparable to this study while in the study of Keshtkaran A et al. ${ }^{22}$ the mean age was 40 years so there is no difference of mean age with the other's results among the patients of haemorrhoidectomy. 
In this series, the mean operative time was 15.04 minutes $(n=50)$, this observation is comparable with the local study of Ali M et al. ${ }^{23}$ who mentioned operative time 9.2 minutes in his study. This is also done by Jayne DG et al. ${ }^{24}$ who revealed that mean operative time was 20 minutes which nearly correlates to this study. The mean duration of hospital stay was 2 days (range 2-4) which is similar to the study of Lai HJ et al. ${ }^{25}$ who showed mean duration of hospital stay 2.8 days (range 2-5) in his stay. Our study showed mostly patients (94\%) were discharged within 24 hours. However some multicenter study ${ }^{26}$ in which $90.3 \%$ of patients were discharged home on 1st postoperative day. This observation correlates well with the study Afridi $\mathrm{N}$ et al. ${ }^{21}$ who reported that $91 \%$ patients were discharged home after one day. Most of patients in our study $70.2 \%$ resumed their normal activities within 7days, which is comparable to other studies. ${ }^{26,27,28}$

In this study, patients operated under local anesthesia had less pain, less analgesic requirements, shorter hospital stay, and less postoperative complications. A shorter operating time and less complications was observed. This is comparable with Castellvi $\mathrm{J}$ et al. ${ }^{29}$ who mentioned the same observations in his study.

\section{CONCLUSION}

This study concluded that diathermy haemorrhoidectomy under local anesthesia is feasible, safe and well tolerated with many short and long term benefits in our environment. It is a good technique and has emerged as an alternative to open haemorrhoidectomy, which is performed in general or spinal anesthesia.

Copyright(C) 21 June, 2016.

\section{REFERENCES}

1. Lunniss PJ. The anus and anal canal. In: Williams NS, Bulstrode CJK, Ronan O'Connell P, eds. Bailey \& Love's Short Practice of Surgery. London: Hodder Arnold; 2008. p. 1253-9.

2. Thomas WHF. The nature of Haemorrhoids. Br J Surg 1975;62(7):542-52.

3. Reese GE, von Roon AC, Tekkis PP. Haemorrhoids. Clin Evid [Online] 2009; 29: 415
4. Saenz EV, Esparza JP, Magro PM, Aquirre JP, Farnandez FA, Rosales JM et al haemorrhoidal disease in a specialty medical center. Rev Gastroenterol Mex 2006; 71:428-32.

5. Milligan EFC morgan cn officer $r$ et al. surgical anatomy of the anal canal and the operative treatment of Haemorrhoids. Lancet 1937; 119-24.

6. Ferguson DJ, Heaton JR. Closed Haemorrhoidectomy. Dis Cilon Rectum 1959; 2(2):176- 9.

7. Qureshi MS, Ali S, Parkash D, Mahar M. Short term clinical outcome of stapled haemorrhoidectomy. J Pak Med Asoc. 2010; 60(5):335-337.

8. Alatise $\mathrm{OI}$, Agbakwurul AE, Takure AO, Adisa AO, Akinkuolie AA. Open hemorrhoidectomy under local anesthesia for symptomatic hemorrhoids; our experience in Ile -Ife, Nigeria. Afr J Health Sci. 2010; 17:42-46.

9. Johansen JF, Sonnenberg A. Constipation is not a risk factor for Haemorrhoids: a case-controlled study of potential etiological agents. Am J Gastroenterol 1994; 89:1981-6.

10. Sikirov D. Comparison of straining during defecation in three positions: Results and implications for human health. Dig Dis.Sci 2003; 48(7):1201-5.

11. Kisli E, AgargunMY, TekinM, Selvi Y, Karaayvaz M. Effects of spinal anesthesia and laryngeal mask anesthesia on mood states during hemorrhoidectomy. Adv Ther. $2007 ; 24: 171-7$.

12. Davies RJ. Haemorrhoids. Clinical evidence.2006; $15: 1-2$.

13. Castellví J, Sueiras A, Espinosa J, Vallet J, Gil V, Pi F. Ligasure versus diathermy hemorrhoidectomy under spinal anesthesia or pudendal block with ropivacaine: a randomized prospective clinical study with 1-year follow-up. Int J Colorectal Dis. 2009 Sep; 24(9):1011-8.

14 Rathore MO, Shukr I Outcome of surgical haemorrhoidectomy by open and closed techniques. Armed Forced J. 2010; 3(4):32-9.

15. Mik M, Rzetecki T, Sygut A, Trzcinski R, Dziki A. Open and closed haemorrhoidectomy for fourth degree haemorrhoids--comparative one center study. Acta Chir lugosl. 2008; 55: 3: 119-25.

16. Ho YH, Buettner PG. Open compared with closed haemorrhoidectomy: meta-analysis of randomized controlled trials. Tech Coloproctol 2007; 11: 2: 135-43. 
17. Alatise OI, Agbakwuru AE, Takure AO, Adisa AO, Akinkuolie AA. Open hemorrhoidectomy under local anesthesia for symptomatic hemorrhoids; our experience in Ile -Ife, Nigeria. Afr J Health Sci. 2010; 16:42-46.

18. Mutihir JT, Aisien AO, Ujah IA. Anaesthetic experience in female sterilization at Jos University Teaching Hospital, Nigeria. East African Medical Journal. 2007; 84:374-378.

19. Vinson - Bonnet B, Coltat JC, Fingerhut A, Bonnet $\mathrm{F}$. Local infiltration with ropivacaine improves immediate postoperative pain control after haemorrhoidal surgery. Diseases of the colon and Rectum. 2002; 45:104-108.

20. Ong $\mathrm{CH}$, Boon Foo EC, Keng FV. Ambulatory circular stapled haemorrhoidectomy under local anaesthesia versus circular stapled haemorrhoidectomy under regional anaesthesia. ANZ Journal of Surgery. 2005; 75:184-186.

21. Afridi N, Nazeem S, Hussain A, Khan M. Initial experience with stapled haemorrhoidectomy for treatment of symptomatic haemorrhoids. J Postgrad Med Inst. 2011; 25(2):143-6.

22. Keshtkaran A, Hosseini SV, Mohammadinia L. ShortTerm Complications of Hemorrhoidectomy in Outpatient and Inpatient Operations in Shiraz, Southern Iran. Iran Red Crescent Med J 2011; 13(4):267-271.
23. Ali M, Hashmi ZA, Zafar A. Haemorrhoidectomy using pudendal nerve block and local infiltration. Gomal $\mathrm{J}$ Med Sci 2010; 8(2):185-89.

24. Jayne DG, Botterill I, Ambrose NS, Brennan TG, Guillou PJ, O'Riordain DS. Randomized clinical trial of Ligasure versus conventional diathermy for day-case haemorrhoidectomy. Br J Surg. 2002 Apr; 89(4):428-32.

25. Lai HJ, Hsiao CW, Kang JC, Chao PC, Wan CC, Jao SW*. Emergency hemorrhoidectomy for treating acute hemorrhoidal crisis: a single institute experience. $J$ Soc Colon Rectal Surgeon (Taiwan) 2006; 17:87-94.

26. Ganio E, Altomare DF, Gabrielli F, Milito G, Canuti S. Prospective randomized multicentre trial comparing stapled with open hemorrhoidectomy. Br J Surg 2001; 88(5):669-74.

27. Walter C, Guilherme C, Coelho F. Initial experience with stapled hemorrhoidopexy for treatment of hemorrhoids. Arq Gastroenterol 2006; 43:3.

28. Riaz AA, Singh A, Patel A, Ali A, Livingstone Jl. Procedure for symptomatic haemorrhoids. BJMP 2008:1:23-7

29. Castellví J, Sueiras A, Espinosa J, Vallet J, Gil V, Pi F. Ligasure versus diathermy hemorrhoidectomy under spinal anesthesia or pudendal block with ropivacaine: a randomized prospective clinical study with 1-year follow-up. Int J Colorectal Dis. 2009 Sep; 24(9):1011-8. Epub 2009 Apr 25.

\section{AUTHORSHIP AND CONTRIBUTION DECLARATION}

\begin{tabular}{|c|c|c|c|}
\hline Sr. \# & Author-s Full Name & Contribution to the paper & Author $=\mathbf{s}$ Signature \\
\hline 1 & Prof. A. Razaque Shaikh & Conception and design & \\
\hline 2 & $\begin{array}{l}\text { Dr. Abdul Ghafoor Dalwani } \\
\text { Dr. Chamna Sushel }\end{array}$ & $\begin{array}{l}\text { Statistical expertise, } \\
\text { Critical revision of the } \\
\text { article for important } \\
\text { intellectual content } \\
\text { Drafting of article }\end{array}$ & \\
\hline 4 & Dr. Ahmed Halepoto & & \\
\hline
\end{tabular}

